\title{
Trait Anxiety and Social Media Fatigue: Fear of Missing Out as a Mediator
}

\author{
Agata H Świątek \\ Małgorzata Szcześniak (D) \\ Grażyna Bielecka
}

Institute of Psychology, University of Szczecin, Szczecin, 7I-017, Poland
Correspondence: Małgorzata Szcześniak Email malgorzata.szczesniak@usz.edu.pl
Background: Interdisciplinary literature indicates different correlates of social media fatigue (hereinafter: SMF). Some studies show that high levels of anxiety may induce lowered Internet use and lead social media users to withdraw from Internet activities. Since the relationship between anxiety and social media use is complex, it is important to investigate mediating factors that may indirectly contribute to or exacerbate this association. Therefore, the main aim of this study is to verify whether fear of missing out (hereinafter: FoMO) is a potential factor accounting for why anxiety is associated with SMF.

Participants, Methods and Data Collection: The research was conducted on a group of 264 adolescents and adults ( $85 \%$ women). The mean age of the respondents was $M=23.76$ with $S D=5.98$ (range $=14-50$ years). The data were collected via online social networking among college students, their family members and friends. The participants answered the Trait Anxiety Scale (TAS), Social Media Fatigue Scale (SMFS), Fear of Missing Out Scale (FoMO), and Revised Life Orientation Test (LOT-R).

Results: The outcomes showed that respondents with higher levels of trait anxiety report more intense cognitive, behavioral, emotional, and overall online fatigue. Concurrently, individuals who experience FoMO on the Internet declare being tired of social media use. Moreover, FoMO mediates the association between trait anxiety and all three dimensions of SMF, and its overall result.

Conclusion: The present research increases our understanding of the possible role of apprehension related to missing out on the anxiety and fatigue connected to engagement in social media. It is possible to assess that trait anxiety might induce higher SMF when individuals experience a general apprehension that others are doing or having things that they do not.

Keywords: anxiety, social media fatigue, fear of missing out, adolescents, adults

\section{Introduction}

There is no consensus on the concept that captures the meaning of the decreasing interest that is found within the number of active users of social media. This phenomenon is typically called social network/networking services/media fatigue. ${ }^{1}$ Since social media fatigue (SMF) is the most commonly used term, we assumed it in the current study.

SMF is a specific type of subjective tiredness related to human activity on the social media platforms. ${ }^{2-4}$ Ravindran et $\mathrm{al}^{5}$ define SMF as

A subjective, multi-dimensional user experience, including sensations such as fatigue, irritation, anger, disappointment, alertness, loss of interest or reduced need/motivation associated with various aspects of using social networks and interaction. 
Bright et $\mathrm{al}^{6,7}$ define SMF as the tendency of users to withdraw from involvement in social networks. The definition found on the Techopedia website describes SMF as

Users' tendency to pull back from social media when they become overwhelmed with too many social media sites, too many friends and followers and too much time spent online maintaining these connections. ${ }^{8}$

A systematic review of previous studies conducted by Dhir et $\mathrm{al}^{2}$ shows that SMF can be considered in the context of online social networking sites and mobile instant messengers.

Although Kang et al $^{9}$ observe that there is little research that explores why people abandon social media, interdisciplinary literature indicates various correlates and determinants of SMF. One of the most common factors regards information overload. When the amount of online information surpasses the human capacity of processing it, individuals may show reduced interest in social media., ${ }^{2,7}$ Other variables associated with SMF that are frequently mentioned are related to difficulties in comprehending and handling privacy concerns and self-disclosure. ${ }^{2,4,7,10-12}$ Still other studies confirm that stress and personal traits ${ }^{13}$ are important antecedents of SMF. However, fewer researchers point to anxiety ${ }^{6,11}$ and fear of missing out $(\text { FoMO })^{11,14}$ as important correlates or causes of SMF although such relationships seem entirely theoretically and empirically justified. Following this line of thought, we assumed that trait anxiety and FoMO may play a relevant role in people's tendency to remove themselves from social media.

Empirical research on the relationship between anxiety and SMF, although relatively recent, ${ }^{2}$ seems very promising. One more widespread line of investigation suggests the existence of negative psychological and physiological consequences of SMF. For example, Dhir et $\mathrm{al}^{2}$ employing a repeated cross-sectional methodology, show that compulsive media use induced SMF among Indian Facebook users, which subsequently resulted in increased anxiety. Pontes ${ }^{15}$ indicate anxiety as one of the outcomes of social media usage among Portuguese school students. Increased media multitasking is associated with higher social anxiety symptoms. ${ }^{16}$ Further, the quantity of time spent using social media leads emerging adults to higher levels of anxiety. ${ }^{17-19}$ Problematic social media is also significantly associated with higher anxiety among the Lebanese population. ${ }^{20}$
Another, less prevalent, ${ }^{9}$ approach, but the one chosen in the present research, denotes anxiety as a cause of SMF. The cogent rationale behind this type of directionality rests on some theoretical perspectives. For example, trait anxiety is considered as a personal property which can affect thoughts, emotions, and behaviors. ${ }^{21}$ Given that the definition of SMF proposed by Zhang et $\mathrm{al}^{12}$ conveys in cognitive (being overwhelmed by the amount of information), emotional (feeling annoyed, irritated or nervous when approaching social media), and behavioral (forgetting the content or lacking new ideas when updating one's status on social media sites) dimensions, it is likely that anxiety may affect SMF. Moreover, the propensity to be anxious expresses itself in a tendency to interpret (or not) stimuli as menacing. ${ }^{22}$ In the case of social media, not all users cease using social networking sites and mobile instant messengers even if there are objective causes to do so. It may indicate that SMF depends, among other traits, also on anxiety.

From an empirical point of view, some studies show that high levels of anxiety may induce lowered social media use. ${ }^{23-25}$ In this regard, Keles et $\mathrm{al}^{26}$ point out that anxiety and psychological distress are more likely to lead social media users to compulsive engagement in Internet activities or to withdraw from them. High anxiety may not only lead to attempts to avoid computers ${ }^{27}$ but even provoke social media burnout. ${ }^{28}$ Such outcomes are understandable if we look at the studies that investigate the effects of personality traits on SMF. For example, Lee et $\mathrm{al}^{29}$ confirm that more neurotic Facebook users, who are inclined to be more anxious and worried, present higher levels of tiredness of social networking sites. Based on the above discussion, the hypothesis is:

H1: Trait anxiety is positively related to SMF.

According to different studies, SMF could be a consequence of FoMO, as well. Bright and Logan ${ }^{14}$ report that a persistent concern about others' rewarding experiences from which one is excluded has a dominant influence of SMF. The feeling of being disconnected from activities that family or friends enjoy indirectly predicts media fatigue over time through mediation of compulsive social media use. ${ }^{2,12}$ Similarly, the urge to keep in permanent contact with others is associated with social media fatigue through problematic social media use. ${ }^{30}$ Zhang et $\mathrm{al}^{31}$ mention FoMO among other relevant stressors of tiredness in the context of social media use, such as: 
perceived overload, compulsive use, time cost, and privacy concerns. Although, in a few other studies, FoMO has no impact on fatigue among social media instant messaging, ${ }^{11}$ which contradicts some prior analyses, we assume that:

$\mathrm{H} 2$ : FoMO is positively associated with SMF.

Keles et $\mathrm{al}^{26}$ suggest that since the relationship between anxiety and social media use is complex, it is important to investigate mediating factors that may indirectly contribute to or exacerbate this association. Until recently, scarce research has been conducted on the existence of an indirect connection between the abovementioned variables. For example, FoMO has been found to be a mediator between personal traits and social media engagement. ${ }^{32}$ Moreover, Elhai et $\mathrm{al}^{33}$ observe that FoMO mediates the relationship between anxiety and the frequency of smartphone use, and the severity of problematic smartphone use among Chinese young adults. These outcomes suggest that FoMO may be an important factor accounting for why anxiety is associated with SMF. More specifically, individuals who tend to report anxiety may experience higher overall levels of FoMO, which, in turn, may be linked to fatigue resulting from social media use. Considering that trait anxiety consists in anticipation of a future threat, ${ }^{34}$ it can be assumed that social media users high in this personality trait may fear being excluded from online social interactions, events, or information. This, in turn, may cause a sense of tiredness related to continuous social media engagement. Therefore, since the knowledge about the potential mechanisms that explain the trait anxiety-SMF relationship is still limited, the third goal of the present study is to examine the mediatory role of FoMO in the relationship between being anxious and experiencing tiredness related to the use of the Internet. Accordingly, we hypothesize that:

H3: FoMO mediates the relationship between trait anxiety and SMF.

\section{Methods and Materials}

\section{Participants}

The research was conducted on a group of 264 adolescents and adults ( $85 \%$ women). The mean age of the respondents was $M=23.76$ with $S D=5.98$ (range $=14-50$ years). The participants were asked how long they had been using social media. More than half of them (55\%) replied with between 5 and 10 years, almost $37 \%$ declared more than 10 years, and $8 \%$ acknowledged less than 5 years. With respect to the declared time spent per day on social media, many participants indicated 3 or more hours (47\%), followed by those who use them for around 3 hours (28\%), 2 hours (18\%), and less than 1 hour (2\%). Only 5\% of participants could not say how much time they spent online. Referring to the use of social media sites, the respondents claimed that they use: Facebook (256 participants); YouTube (235); Instagram (188); WhatsApp (90); Snapchat (85); TikTok (77); Pinterest (51); Twitter (22); LinkedIn (8); and ResearchGate (3).

\section{Data Collection}

In the current study, the data were collected via online social networking. We used a convenience sampling approach among the University of Szczecin students who were encouraged to tell their family members and friends to sign up to participate in the research. A principal criterion of taking part in the study was to use at least one of the social media platforms (eg: Facebook, YouTube, Instagram, etc.). All respondents were notified about the aim of the study, disclosed their willingness to take part in it, and signed informed and written consent for their participation in the research. They were also assured of the confidentiality of their information. The underage participants were admitted to the study after obtaining their parents'/guardians' consent. The study protocol was approved by the Bioethics Committee of the Institute of Psychology at the University of Szczecin (KB 2/2021) and performed in accordance with Declaration of Helsinki.

\section{Measurement Anxiety}

The Trait Anxiety Scale is a Polish tool (Skala Lęk-Cecha, SL-C) designed by Piksa et $\mathrm{al}^{35}$ to measure the intensity of anxiety understood as a personality trait. The scale assesses the tendency to perceive a situation as threatening or to predict future events in terms of danger. Such anxiety manifests itself by characteristic symptoms on the cognitive (eg: "I have recurring thoughts that I cannot let go of"), behavioral (eg: "I have trouble falling asleep"), emotional (eg: "I feel like I am more sensitive than others"), and somatic (eg: "My muscles feel tense") levels. The SL$\mathrm{C}$ is a valid one-factor tool and consists of 15 items. Answers are given on a 4-point scale, where the answer "often" = three points, and the answer "never" = zero points. Two statements (9 and 11) are reverse scored. The SL-C score is the sum of all points. The possible 
scores range from 0 (minimum trait anxiety intensity) to 45 (maximum trait anxiety intensity). The original Cronbach's $\alpha$ coefficient was 0.86 , while in the present study, $\alpha$ was 0.90 .

\section{Social Media Fatigue}

The Social Media Fatigue Scale (SMFS) was developed by Zhang et $\mathrm{al}^{12}$ and adapted into Polish by Świątek et al. ${ }^{1}$ It is a 15-item scale which measures three dimensions of tiredness with social networks. The cognitive dimension refers to information overload (eg: "I am frequently overwhelmed by the amount of information available on social media sites"). The behavioral dimension manifests itself in the form of forgetting activities that were supposed to be performed (eg: "I am likely to forget the content of the status that I intended to repost"). The emotional dimension includes the unpleasant emotions associated with logging into an account and receiving different notifications or invitations (eg: "I feel nervous when receiving friend request on social media sites"). Each of the subscales contains 5 items. The respondent gives answers on a seven-point scale, where 1 means "totally disagree" and 7 means "totally agree." The overall score (sum of all points obtained) can range between 15 and 75 . The higher the sum, the more intense the social media fatigue. The exploratory factor analysis showed that 15 items loaded strongly to 3 factors, exactly as in the Chinese version of the SMFS. Cognitive fatigue accounted for $42.131 \%$ of the total variance, behavioral $-10.158 \%$, and emotional $-8.717 \%$. The values of the internal consistency obtained in the present study for the cognitive $\left(\alpha_{\operatorname{cog}}=0.85\right)$, behavioral $\left(\alpha_{\text {beh }}=0.83\right)$, and emotional $\left(\alpha_{\text {emot }}=0.79\right)$ dimensions were considered satisfactory. The Cronbach's alpha for the 15 -item SMFS was $\alpha_{\text {smfs }}$ $=0.89$.

\section{Fear of Missing Out}

The Fear of Missing Out Scale (FoMO) developed by Przybylski et $\mathrm{al}^{36}$ and translated into Polish by Tomczyk $^{37}$ was used to measure the sense that others are having a gratifying experience which one is absent from. The scale is a one-factor 10-item self-report tool that relates to anxiety about the need to keep up-to-date with what is happening with others in the context of social media (eg: "I get anxious when I do not know what my friends are up to"). The respondents rate each item on a 5-point Likert scale, where 1 means "not at all true of me" and 5 means "extremely true of me." The total sum ranges between 10 and 50, where 50 indicates higher levels of fear of missing out. The Cronbach's coefficient of the original version of the scale presented very good internal consistency $(\alpha=0.90)$ and the $\alpha$ in the present study demonstrated good reliability $(\alpha=0.82)$.

\section{Revised Life Orientation Test}

The Revised Life Orientation Test (LOT-R) developed by Scheier et $\mathrm{al}^{38}$ and translated into Polish by Juczyński ${ }^{39}$ was used to measure self-reported dispositional optimism. The questionnaire includes 10 items from 1 which means "strongly disagree" to 7 which means "strongly agree." The Cronbach's $\alpha$ coefficient of the original version of the scale presented good internal consistency (between $\alpha=$ 0.70 and $\alpha=0.80$ ) and the $\alpha$ in the present study demonstrated good reliability ( $\alpha=0.82$ ). This test was chosen to check for a possible confounding variable.

\section{Statistical Analysis}

All of the analyses were conducted using the IBM SPSS Statistics 23.0 software and the PROCESS macro for SPSS. Descriptive statistics of the means, standard deviation, skewness, and kurtosis were checked, with the normality assumption met in the case of all of the variables considered in the current study. The internal reliability (Cronbach's $\alpha$ ) was calculated for all factors employed. The correlation analysis was performed using Pearson's $r$ coefficient. A regression analysis was adopted to diagnose multicollinearity since we expected a rather strong correlation between trait anxiety and FoMO. The regression model was also used to check the data for possible outliers. We computed the Mahalanobis distance and Cook's distance. The participants' sex, age, dispositional level of optimism, and hours and years of time spent online were included to control for their implicit effect on the association between trait anxiety, considered as the independent variable, and SMF in its cognitive, behavioral, emotional, and overall dimensions. There are some theoretical and empirical grounds for the examination of the confounders mentioned above. Firstly, according to Zhang et al, ${ }^{40}$ males are more likely to suffer from SMF than females. However, Jackson et $\mathrm{al}^{41}$ suggest that women tend to report more computer anxiety than men. With regard to optimism, it seems that a lower level of this personality trait may be related to problematic Internet use. $^{42}$ With respect to age, it is well supported that younger users of social media are inclined to use more technologies and be more frequent users of different 
domains of the Internet. ${ }^{43}$ Finally, there is some evidence that the average weekday time correlates positively with problematic Internet use. ${ }^{44}$

The PROCESS macro for SPSS (version 3.2) was run to establish the extent to which trait anxiety influences SMF through FoMO. Trait anxiety was the independent variable and SMF was the dependent variable (cognitive, behavioral, emotional dimension, overall result). FoMO was included as a mediating variable. Thus, there were four single-level mediation models no. $4,{ }^{45}$ involving three-variable systems. For the present analysis, the $95 \%$ confidence interval of the indirect effects was calculated using 5000 bootstrapped resamples. This method appears to be superior to traditional mediation analyses because it does not require the data to adhere to assumptions of normality. ${ }^{46}$

\section{Results}

\section{Descriptive Statistics and Initial Analysis}

The values of the mean, standard deviation, skewness, and kurtosis tests are presented in Table 1. Despite statistically significant $(p<0.001)$ values of the normality test, the skewness and kurtosis values were in a relatively low range of \pm 1 . Therefore it was found that the deviation from the normal distribution is not meaningful and the variables of trait anxiety, fear of missing out, cognitive, behavioral, emotional, and overall media fatigue, and life orientation were close to the normal distribution.

\section{Multicollinearity and Confounding Variables}

Although no agreement exists with regard to which the Variance Inflation Factor (VIF) cut-off score most closely corresponds with collinearity, we accepted a VIF index

Table I Descriptive Statistics for Trait Anxiety, Fear of Missing Out, Social Media Fatigue, and Life Orientation ( $N=264)$

\begin{tabular}{|l|c|c|c|c|}
\hline Variable & $\boldsymbol{M}$ & SD & Skewness & Kurtosis \\
\hline SL_C & 41.27 & 9.35 & -0.370 & -0.369 \\
FoMO & 29.44 & 7.89 & 0.157 & -0.323 \\
SMFS_C & 18.93 & 7.71 & 0.029 & -0.851 \\
SMFS_B & 15.13 & 7.50 & 0.487 & -0.497 \\
SMFS_E & 14.11 & 6.89 & 0.642 & -0.196 \\
SMFS_O & 48.18 & 18.53 & 0.291 & -0.420 \\
LOT-R & 18.03 & 6.27 & -0.081 & -0.942 \\
\hline
\end{tabular}

Abbreviations: SL_C, trait anxiety; FoMO, fear of missing out; SMFS_C, cognitive social media fatigue; SMFS_B, behavioral social media fatigue; SMFS_E, emotional social media fatigue; SMFS_O, overall social media fatigue; LOT_R, revised life orientation test. higher than $5.0^{47}$ and a tolerance value of less than 0.2 as characteristic of multicollinearity. ${ }^{48}$ On the grounds that the analysis of multiple regression provided a VIF of 1.082.08 and a tolerance rate starting from of 0.48 to 0.93 , the multicollinearity indexes indicated little demonstration of multicollinearity for these data. The Mahalanobis distance procedure was adopted, using the chi-square distribution with a probability estimate of $p<0.001$ for a case being an outlier. $^{49}$ Three of 264 cases were classified as presumed multivariate outliers (the lowest values of $p$ were: 0.00004 , 0.00018, and 0.00043). However, since the correlational and mediational statistics with and without outliers were compatible, we opted to retain the matrix with the three detected outliers. Additionally, Cook's value (between 0.000 and 0.085 ) was under the point at which the researcher should be apprehensive, that is, less than $1,{ }^{49}$ implying that the cases are not problematic in relation to having a significant impact on the model. ${ }^{50}$ Hierarchical regression analyses showed that none of sex, age, dispositional level of optimism, nor hours or years spent online made a considerable unique contribution to the model, explaining only $6.6 \%$ of the variance $\left(\mathrm{R}^{2}=0.066\right)$ : sex $(\beta=-0.107, \mathrm{t}=-1.967, p=0.050)$, dispositional level of optimism $(\beta=0.113, \mathrm{t}=1.686, p=0.093)$, age $(\beta=0.070$, $\mathrm{t}=1.176, p=0.241)$, hours spent online $(\beta=-0.062, \mathrm{t}=$ $-1.131, p=0.259)$, and years spent online $(\beta=0.019, \mathrm{t}=$ $0.342, p=0.733)$. The predictors explained an additional $23 \%$ of the variance even after controlling for the effects of potential confounders.

\section{Correlations}

Congruent with the hypotheses ( $\mathrm{H} 1$ and $\mathrm{H} 2)$, trait anxiety correlated positively with all three dimensions of SMF and its overall outcome (Table 2). Specifically, the results suggest that participants with higher levels of trait anxiety report more intense cognitive, behavioral, emotional, and overall online fatigue. Hence, anxious Internet users display fatigue related to social media. Concurrently, FoMO presented a similar pattern of results, showing a positive association with the three dimensions of SMF and its overall outcome. Therefore, it can be assumed that individuals who experience fear of missing out declare being tired of social media use.

\section{Mediation}

For the purpose of further investigation of the relationship between the assessment of trait anxiety and cognitive, behavioral, emotional, and overall SMF, FoMO was 
Table 2 Correlations Between Dimensions of SMFS, FoMO, and SL_C $(N=264)$

\begin{tabular}{|l|c|c|c|c|c|c|}
\hline & SMFS_C & SMFS_B & SMFS_E & SMFS_O & FoMO & SL_C \\
\hline SMFS_C & $\mathrm{I}$ & & & & & \\
SMFS_B & $0.562^{* * *}$ & $\mathrm{I}$ & & & \\
SMFS_E & $0.591^{* * *}$ & $0.507^{* * *}$ & $\mathrm{I}$ & & \\
SMFS_O & $0.863^{* * *}$ & $0.827^{* * *}$ & $0.823^{* * *}$ & $\mathrm{I}$ & \\
FoMO & $0.360^{* * *}$ & $0.486^{* * *}$ & $0.414^{* * *}$ & $0.501^{* * *}$ & $\mathrm{I}$ & \\
SL_C & $0.299^{* * *}$ & $0.328^{* * *}$ & $0.287^{* * *}$ & $0.364^{* * *}$ & $0.529 * * *$ & $\mathrm{I}$ \\
\hline
\end{tabular}

Note: $* * * p<0.001$.

Abbreviations: SMFS_C, cognitive social media fatigue; SMFS_B, behavioral social media fatigue; SMFS_E, emotional social media fatigue; SMFS_O, overall social media fatigue; FoMO, fear of missing out; SL_C, trait anxiety.

introduced as a potential mediator which has an effect on the existing relationship between the independent variable (trait anxiety) and the dependent variable (cognitive, behavioral, emotional, and overall SMF) (Figure 1).

The PROCESS macro for SPSS (Table 3) showed that the direct effect (c path) decreased in value after the introduction of fear of missing out in all four models (c' path). Consistent with the detected results, it can be asserted that FoMO mediated the association between trait anxiety and all three dimensions of, and overall SMF.

\section{Discussion}

The aim of the present study was to verify whether: 1) trait anxiety is positively related to SMF; 2) FoMO is positively associated with SMF; and 3) FoMO mediates the relationship between trait anxiety and SMF. All hypotheses found their confirmation, being consistent with previous research.

Firstly, the positive association between trait anxiety and fatigue related to social media use may be explained through some studies which show that people who display higher levels of neuroticism and negative affectivity tend to be drawn to social networking sites more than their less neurotic counterparts. ${ }^{51}$ Since neuroticism and trait anxiety are strongly coinciding constructs, it is cogent to expect that an anxious predisposition might coexist with SMF. Consequently, if lower emotional stability predicts the likelihood to engage excessively in different online activities, this could mean that individuals who have a tendency toward anxiety may also demonstrate more intense SMF than those who are less anxious. By analogy, since socially anxious individuals are generally vulnerable to problematic Internet use, ${ }^{16,52-54}$ it may mean that generally anxious people become tired of constantly using social media, as well. Indeed, Teng et $\mathrm{al}^{55}$ report that anxiety and fatigue are considered dominant factors within the context of negative usage of social media.

Secondly, FoMO correlates positively with SMF, thus suggesting that a pervading concern that others might be having fulfilling experiences which one is lacking ${ }^{36}$ can result in a tendency to retreat from social media usage. Being overwhelmed by the continuous FoMO might lead to a subjective feeling of tiredness and avoidance of social media. In fact, a continuous urge to keep in touch and share moments with other Internet users was found to affect reduced interest in social media and boredom. ${ }^{56}$ Moreover, individuals with higher levels of FoMO tended to check their social media more frequently than those

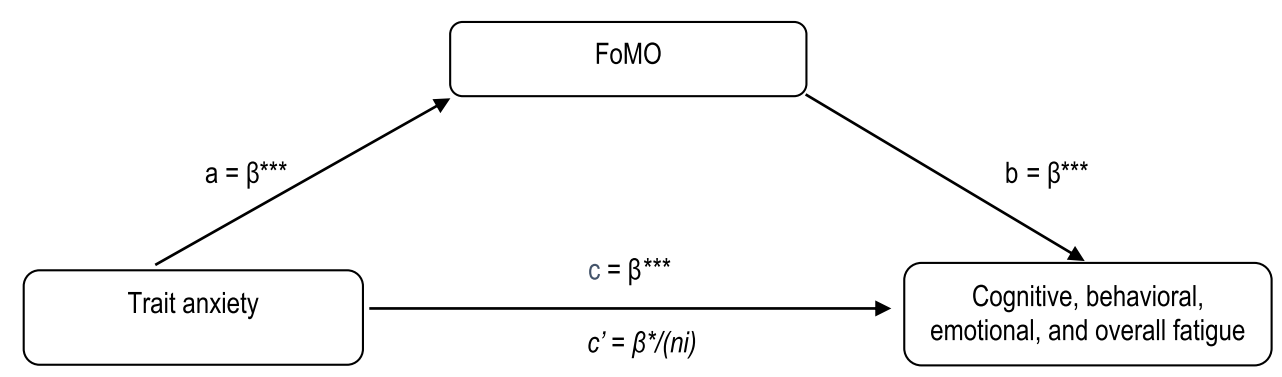

Figure I Theoretical model of the role of FoMO in the relationship between trait anxiety and cognitive, behavioral, emotional, and overall social media fatigue. Notes: ${ }^{*} p<0.05 ; * * * p<0.001$.

Abbreviation: ni, nonsignificant. 
Table 3 Role of Fear of Missing Out in the Relationship Between Trait Anxiety and Dimensions of Social Media Fatigue

\begin{tabular}{|l|l|l|l|c|c|c|c|c|}
\hline & a path & b path & c path & c' path & Indirect Effect & B (SE) & Lower Cl & Upper Cl \\
\hline TA - F - CF & $0.44 * * *$ & $0.27^{* * *}$ & $0.24 * * *$ & $0.12^{*}$ & 0.1221 & 0.0326 & 0.0582 & 0.1859 \\
$\mathrm{TA}-\mathrm{F}-\mathrm{BF}$ & $0.44 * * *$ & $0.26 * * *$ & $0.41^{* * *}$ & $0.07(\mathrm{ni})$ & 0.1844 & 0.0362 & 0.1173 & 0.2593 \\
$\mathrm{TA}-\mathrm{F}-\mathrm{EF}$ & $0.44 * * *$ & $0.31 * * *$ & $0.21^{* * *}$ & $0.06(\mathrm{ni})$ & 0.1420 & 0.0324 & 0.0814 & 0.2096 \\
$\mathrm{TA}-\mathrm{F}-\mathrm{OF}$ & $0.44 * * *$ & $1.00^{* * *}$ & $0.72 * * *$ & $0.27 *$ & 0.4485 & 0.0873 & 0.2880 & 0.6279 \\
\hline
\end{tabular}

Notes: $*_{p}<0.05 ; *^{* * *} p<0.001$.

Abbreviations: ni, nonsignificant; TA, trait anxiety; F, fear of missing out; CF, cognitive fatigue; BF, behavioral fatigue; EF, emotional fatigue; OF, overall fatigue.

who have lower FoMO in order to keep pace with their friends' plans. ${ }^{32}$ Hence, constantly seeking out updates may produce a feeling of exhaustion.

Finally, FoMO mediates the relationship between trait anxiety and SMF. In other words, our findings suggest that trait anxiety might induce higher SMF when individuals experience a general apprehension that others are doing or having things that they do not. Since trait anxiety expresses the general tendency to be upset in stressful situations, ${ }^{57}$ it is understandable that the feeling of being absent from important or rewarding events happening elsewhere might lead to tiredness of social media. Moreover, trait anxiety is associated with anticipation of distress ${ }^{58}$ and the negative interpretation of specific ambiguous situations. ${ }^{59}$ Hence, anxiety may lead to fear of being excluded from online social interactions which, in turn, can cause a sense of tiredness related to continuous social media engagement.

\section{Limitations}

Despite the study's strengths, it is not without limitations. Although the findings attested the hypothesized mediatory model, the cross-sectional character of the data collected at a single point in time does not consent to provide causal conclusions. We recognize that in future studies, researchers should consider alternative designs based on longitudinal and experimental approaches which are regarded to have substantial predictive value. Moreover, obtaining significant statistical effects from mediation analyses does not imply that FoMO is a mediator in the relationship between trait anxiety and SMF. It can also be assumed that anxiety might be a result of higher SMF, as shown by other researchers. ${ }^{2,16-19}$ In our study, there was also an unequal ratio of women to men. Therefore, in future research, greater participation of male respondents should be provided. Finally, the recruitment of the sample set solely online could distort the data given the study's focus on social media. It would be beneficial to conduct similar studies in the traditional way, in the form of paper and pencil.

\section{Conclusion}

To our knowledge, there are no studies on the mediatory effect of FoMO on the relationship between trait anxiety and SMF. Therefore, the present research increases our understanding of the possible role of apprehension related to missing out on the anxiety and fatigue connected to the engagement in social media. It is possible to assess that people who feel absent from others' rewarding experiences shared online suffer from stronger anxiety and show higher levels of SMF.

\section{Data Sharing Statement}

The datasets used during the current study are available from the corresponding author.

\section{Acknowledgment}

The authors thank the study participants who completed the questionnaires.

\section{Author Contributions}

All authors made a significant contribution to the work reported, whether that is in the conception, study design, execution, acquisition of data, analysis and interpretation, or in all these areas; took part in drafting, revising or critically reviewing the article; gave final approval of the version to be published; have agreed on the journal to which the article has been submitted; and agree to be accountable for all aspects of the work.

\section{Disclosure}

The authors report no conflicts of interest in this work. 


\section{References}

1. Świątek AH, Szcześniak M, Zhang S, Borkowska H, Preliminary A. Validation of the Polish version of the social media fatigue scale. Psychol Res Behav Manag. 2021;14:719-729. doi:10.2147/PRBM. S312897

2. Dhir A, Yossatorn Y, Kaur P, Chen S. Online social media fatigue and psychological wellbeing-a study of compulsive use, fear of missing out, fatigue, anxiety and depression. Int $J$ Inf Manag. 2018;40:141-152. doi:10.1016/j.ijinfomgt.2018.01.012

3. Xiao L, Mou J, Huang L. Exploring the antecedents of social network service fatigue: a socio-technical perspective. IMDS. 2019;119 (9):2006-2032. doi:10.1108/IMDS-04-2019-0231

4. Lee AR, Son SM, Kim KK. Information and communication technology overload and social networking service fatigue: a stress perspective. Comput Hum Behav. 2016;55:51-61. doi:10.1016/j. chb.2015.08.011

5. Ravindran T, Kuan ACY, Lian DGH. Antecedents and effects of social network fatigue. J Assoc Inf Sci Technol. 2014;65 (11):2306-2320. doi:10.1002/asi.23122

6. Bright LF, Kleiser SB, Grau SL. Too much Facebook? An exploratory examination of social media fatigue. Comput Hum Behav. 2015;44:148155. doi:10.1016/j.chb.2014.11.048

7. Logan K, Bright LF, Grau SL. "Unfriend me, please!": social media fatigue and the theory of rational choice. $J$ Mark Theory Pract. 2018;26(4):357-367. doi:10.1080/10696679.2018.148819

8. Techopedia. Definition of social media fatigue. Available from: https://www.techopedia.com/definition/27372/social-media-fatigue. Accessed August 6, 2021.

9. Kang I, Zhang Y, Yoo S. Elaboration of social media performance measures: from the perspective of social media discontinuance behavior. Sustainability. 2020;12:7962. doi:10.3390/su12197962

10. Fan X, Jiang X, Deng N, Dong X, Lin Y. Does role conflict influence discontinuous usage intentions? Privacy concerns, social media fatigue and self-esteem. Inf Technol People. 2020. doi:10.1108/itp-082019-0416

11. Malik A, Dhir A, Kaur P, Johri A. Correlates of social media fatigue and academic performance decrement: a large cross-sectional study. Inf Technol People. 2020;34(2):557-580. doi:10.1108/ITP-06-20190289

12. Zhang S, Shen Y, Xin T, Sun H, Wang Y, Zhang X. The development and validation of a social media fatigue scale: from a cognitive-behavioral-emotional perspective. PLoS One. 2021;16(1): e0245464. doi:10.1371/journal.pone.0245464

13. Xiao L, Mou J. Social media fatigue - technological antecedents and the moderating roles of personality traits: the case of WeCHat. Comput Hum Behav. 2019;101:297-310. doi:10.1016/j.chb.2019. 08.001

14. Bright LF, Logan K. Is my fear of missing out (FOMO) causing fatigue? Advertising, social media fatigue, and the implications for consumers and brands. INTR. 2018;28(5):1213-1227. doi:10.1108/ IntR-03-2017-0112

15. Pontes HM. Investigating the differential effects of social networking site addiction and internet gaming disorder on psychological health. J Behav Addict. 2017;6(4):601-610. doi:10.1556/2006.6.2017.075

16. Becker MW, Alzahabi R, Hopwood CJ. Media multitasking is associated with symptoms of depression and social anxiety. Cyberpsychol Behav Soc Netw. 2013;16(2):132-135. doi:10.1089/cyber.2012.0291

17. Tsitsika AK, Tzavela EC, Janikian M, et al. Online social networking in adolescence: patterns of use in six European countries and links with psychosocial functioning. $J$ Adolesc Health. 2014;55 (1):141-147. doi:10.1016/j.jadohealth.2013.11.010

18. Woods HC, Scott H. \#Sleepyteens: social media use in adolescence is associated with poor sleep quality, anxiety, depression and low selfesteem. $J$ Adolesc. 2016;51:41-49. doi:10.1016/j.adolescence. 2016.05.008
19. Vanucci A, Flannery KM, McCauley Ohannessian C. Social media use and anxiety in emerging adults. $J$ Affect Disord. 2017;207:163-166. doi:10.1016/j.jad.2016.08.040

20. Dagher M, Farchakh Y, Barbar S, et al. Association between problematic social media use and memory performance in a sample of Lebanese adults: the mediating effect of anxiety, depression, stress and insomnia. Head Face Med. 2021;17:6. doi:10.1186/s13005-02100260-8

21. Heeren A, Bernstein EE, McNally RJ. Deconstructing trait anxiety: a network perspective. Anxiety Stress Coping. 2018;31(3):262-276. doi:10.1080/10615806.2018.1439263

22. Guil R, Gómez-Molinero R, Merchan-Clavellino A, Gil-Olarte P, Zayas A. Facing anxiety, growing up. Trait emotional intelligence as a mediator of the relationship between self-esteem and university anxiety. Front Psychol. 2019;10:567. doi:10.3389/fpsyg.2019.00567

23. Paul N, Glassman M. Relationship between internet self-efficacy and internet anxiety: a nuanced approach to understanding the connection. Australas J Educ Technol. 2017;33(4). doi:10.14742/ ajet.2791

24. Islam AKMN, Laato S, Talukder S, Sutinen E. Misinformation sharing and social media fatigue during COVID-19: an affordance and cognitive load perspective. Technol Forecast Soc Change. 2020;159:120201. doi:10.1016/j.techfore.2020.120201

25. Cao X, Yu L. Exploring the influence of excessive social media use at work: a three-dimension usage perspective. Int $J$ Inf Manag. 2019;46:83-92. doi:10.1016/j.ijinfomgt.2018.11.019

26. Keles B, McCrae N, Grealish A. A systematic review: the influence of social media on depression, anxiety and psychological distress in adolescents. Int J Adolesc Youth. 2020;25(1):79-93. doi:10.1080/ 02673843.2019.1590851

27. Beckers JJ, Schmidt HG. Computer experience and computer anxiety. Comput Hum Behav. 2003;19(6):785-797. doi:10.1016/s07475632(03)00005-0

28. Liu C, Ma J. Social media addiction and burnout: the mediating roles of envy and social media use anxiety. Curr Psychol. 2018;39:1883-1891. doi:10.1007/s12144-018-9998-0

29. Lee CC, Chou STH, Huang YR. A study on personality and social media fatigue - example of Facebook users. Lect Notes Info Theory. 2014;2(3):249-253. doi:10.12720/Init.2.3.249-253

30. Shen Y, Na T, Chai Y. The internet and the space-time flexibility of daily activities: a case study of Beijing, China. Cities. 2020;97:102493. doi:10.1016/j.cities.2019.102493

31. Zhang Y, He W, Peng L. How perceived pressure affects users' social media fatigue behavior: a case on WeChat. J Comput Inf Syst. 2020. doi:10.1080/08874417.2020.1824596

32. Oberst U, Wegmann E, Stodt B, Brand M, Chamarro A. Negative consequences from heavy social networking in adolescents: the mediating role of fear of missing out. $J$ Adolesc. 2017;55:51-60. doi:10.1016/j.adolescence.2016.12.008

33. Elhai JD, Levine JC, Dvorak RD, Hall BJ. Fear of missing out need for touch anxiety and depression are related to problematic smartphone use. Comput Hum Behav. 2016;63:509-516. doi:10.1016/j. chb.2016.05.079

34. MacLeod AK, Byrne A. Anxiety, depression, and the anticipation of future positive and negative experiences. $J$ Abnorm Psychol. 1996;105(2):286-289. doi:10.1037//0021-843x.105.2.286

35. Piksa M, Kosiorowska E, Golonka K. Skala Lęku-Cecha (SL-C). ResearchGate. 2020:1-4. Polish. doi:10.13140/RG.2.2.17148.36484/ 3

36. Przybylski AK, Murayama K, DeHaan CR, Gladwell V. Motivational, emotional, and behavioral correlates of fear of missing out. Comput Hum Behav. 2013;29:1841-1848. doi:10.1016/j. chb.2013.02.014

37. Tomczyk Ł; FOMO Among Polish Adolescents. Fear of missing out as a diagnostic and educational challenge. Trends and applications. Inf Sys Technol. 2021;565-574. doi:10.1007/978-3-030-72657-7_54 
38. Scheier MF, Carver C, Bridges MW. Distinguishing optimism from neuroticism (and trait anxiety, self-mastery, and self-esteem): a reevaluation of the life orientation test. J Pers Soc Psychol. 1995;67(6):1063-1078. doi:10.1037/0022-3514.67.6.1063

39. Juczyński Z. Narzędzia Pomiaru w Promocji i Psychologii Zdrowia. Warszawa: Pracownia Testów Psychologicznych; 2009.

40. Zhang S, Zhao L, Lu Y, Yang J. Do you get tired of socializing? An empirical explanation of discontinuous usage behaviour in social network services. Inf Manag. 2016;53(7):904-914. doi:10.1016/j. im.2016.03.006

41. Jackson LA, Ervin KS, Gardner PD, Schmitt N. Gender and the internet: women communicating and men searching. Sex Roles. 2001;44(5-6):363-379. doi:10.1023/A:1010937901821

42. Hinić D, ZototiC M, Beara M, Rakić-Bajić G. Relationship of problematic internet use and positive orientation indicators in adolescents. Psihologija. 2020;53(4):341-357. doi:10.2298/ PSI190720018H

43. Olson KE, O'Brien MA, Rogers WA, Charness N. Diffusion of technology: frequency of use for younger and older adults. Ageing Int. 2011;36(1):123-145. doi:10.1007/s12126-010-9077-9

44. Beutel ME, Brähler E, Glaesmer H, Kuss DJ, Wölfling K, Müller KW. Regular and problematic leisure-time Internet use in the community: results from a German population-based survey. Cyberpsychol Behav Soc Netw. 2011;14(5):291-296. doi:10.1089/ cyber.2010.0199

45. Hayes AF. Introduction to Mediation, Moderation and Conditional Process Analysis. A Regression-Based Approach. New York, NY: The Guilford Press; 2013.

46. George D, Mallery P. IBM SPSS Statistics 23 Step by Step. A Simple Guide and Reference. New York, NY: Routledge; 2016.

47. Hair JF, Hult GTM, Ringle CM, Sarstedt MA. Primer on Partial Least Squares Structural Equation Modeling (PLS-SEM). Thousand Oaks, CA: SAGE Publications; 2016.

48. Mehmetoglu M, Jakobsen TG. Applied Statistics Using Stata: A Guide for the Social Sciences. London, UK: SAGE Publications; 2017.
49. Fidell LS, Tabachnick GB. Preparatory data analysis. In: Schinka JA, Velicer WF, editors. Handbook of Psychology: Research Methods in Psychology. Hoboken, NJ: John Wiley \& Sons; 2003:115-141.

50. Lomax RG, Hahs-Vaughn DL. An Introduction to Statistical Concepts. New York, NY: Routledge; 2012.

51. Correa T, Hinsley AW, de Zuniga HG. Who interacts on the Web? The intersection of users' personality and social media use. Comput Hum Behav. 2010;26:247-253. doi:10.1016/j.chb.2000.09.003

52. Caplan S, Williams D, Yee N. Problematic internet use and psychosocial well-being among MMO players. Comput Hum Behav. 2009;25(6):1312-1319. doi:10.1016/j.chb.2009.06.006

53. Lee BW, Stapinski LA. Seeking safety on the internet: relationship between social anxiety and problematic internet use. J Anxiety Disord. 2021;26(1):197-205. doi:10.1016/j.anxdis.2011.11.001

54. Erliksson OJ, Lindner P, Mörtberg E. Measuring associations between social anxiety and use of different types of social media using the Swedish social anxiety scale for social media users: a psychometric evaluation and Cross-Sectional Study. Scand J Psychol. 2020;61(6):819-826. doi:10.1111/sjop.12673

55. Teng L, Liu D, Luo J. Explicating user negative behavior toward social media: an exploratory examination based on stressor-strainoutcome model. Cogn Technol Work. 2021. doi:10.1007/s10111-02100665-0

56. Al-Saggaf Y. Phubbing, fear of missing out and boredom. J Technol Behav Sci. 2020. doi:10.1007/s41347-020-00148-5

57. Balta S, Emirtekin E, Kircaburun K, Griffiths MD. Neuroticism, trait fear of missing out, and phubbing: the mediating role of state fear of missing out and problematic Instagram use. Int J Ment Health Addict. 2018;18:628-639. doi:10.1007/s11469-018-9959-8

58. Maner JK, Richey JA, Cromer K, et al. Dispositional anxiety and risk-avoidant decision-making. Pers Individ Dif. 2007;42:665-675. doi:10.1016/j.paid.2006.08.016

59. Bögels SM, Zigterman D. Dysfunctional cognitions in children with social phobia, separation anxiety disorder, and generalized anxiety. J Abnorm Child Psychol. 2000;28:205-211. doi:10.1023/ A: 1005179032470
Psychology Research and Behavior Management

\section{Publish your work in this journal}

Psychology Research and Behavior Management is an international, peer-reviewed, open access journal focusing on the science of psychology and its application in behavior management to develop improved outcomes in the clinical, educational, sports and business arenas. Specific topics covered in the journal include: Neuroscience, memory and decision making; Behavior modification and management; Clinical applications; Business and sports performance management; Social and developmental studies; Animal studies. The manuscript management system is completely online and includes a very quick and fair peer-review system, which is all easy to use. Visit http://www. dovepress.com/testimonials.php to read real quotes from published authors. 